Original article

\title{
Prescribing patterns of antidepressants in Europe: Results from the Factors Influencing Depression Endpoints Research (FINDER) study ${ }^{\text {i }}$
}

\author{
Michael Bauer $^{\mathrm{a}, *}$, Brigitta U. Monz ${ }^{\mathrm{b}, 1}$, Angel L. Montejo ${ }^{\mathrm{c}, 2}$, Deborah Quail ${ }^{\mathrm{d}, 3}$, \\ Nicolas Dantchev e,4, Koen Demyttenaere ${ }^{\text {f,5 }}$, Ana Garcia-Cebrian ${ }^{\text {d,6 }}$, Luigi Grassi ${ }^{\text {g,7 }}$, \\ David G.S. Perahia $^{\mathrm{d}, \mathrm{h}, 8}$, Catherine Reed ${ }^{\mathrm{d}, 9}$, Andre Tylee $^{\mathrm{i}, 10}$ \\ ${ }^{a}$ Department of Psychiatry and Psychotherapy, University Hospital Carl Gustav Carus, Technische Universität Dresden, \\ Fetscherstraße 74, D-01307 Dresden, Germany \\ ${ }^{\mathrm{b}}$ Boehringer Ingelheim GmbH, D-55216 Ingelheim, Germany \\ ${ }^{\mathrm{c}}$ University Hospital of Salamanca, Avda Comuneros 27, Salamanca 37003, Spain \\ ${ }^{\mathrm{d}}$ Eli Lilly and Company Limited, Lilly Research Centre, Erl Wood Manor, Sunninghill Road, Windlesham, Surrey, GU20 6PH, UK \\ ${ }^{\mathrm{e}}$ Unité de Psychiatrie, Hôtel-Dieu, 1, place du Parvis Notre Dame, 75004 Paris, France \\ ${ }^{\mathrm{f}}$ Universitair Ziekenhuis Gasthuisberg, Herestraat 49, 3000 Leuven, Belgium \\ ${ }^{\mathrm{g}}$ Section of Psychiatry, University of Ferrara, Corso Giovecca 203, 44100 Ferrara, Italy \\ ${ }^{\mathrm{h}}$ The Gordon Hospital, Bloomburg Street, London, SW1V 2RH, UK \\ ${ }^{i}$ Section of Primary Care Mental Health, Health Services and Population Research Department, Institute of Psychiatry, \\ De Crespigny Park, Denmark Hill, London, SE5 8AF, UK
}

Received 2 April 2007; received in revised form 17 October 2007; accepted 2 November 2007

\footnotetext{
Abstract

Antidepressant prescribing patterns and factors influencing the choice of antidepressant for the treatment of depression were examined in the Factors Influencing Depression Endpoints Research (FINDER) study, a prospective, observational study in 12 European countries of 3468 adults about to start antidepressant medication for their first episode of depression or a new episode of recurrent depression. Selective serotonin reuptake inhibitors (SSRIs) were the most commonly prescribed antidepressant (63.3\% patients), followed by serotonin-norepinephrine reuptake inhibitors (SNRIs, 13.6\%), but there was considerable variation across countries. Notably, tricyclic and tetracyclic antidepressants (TCAs) were prescribed for $26.5 \%$ patients in Germany. The choice of the antidepressant prescribed was strongly influenced by the previous use of antidepressants, which was significantly associated with the prescription of a SSRI (OR 0.64; 95\% CI 0.54, 0.76), a SNRI (OR 1.49; 95\% CI 1.18, 1.88 ) or a combination of antidepressants (OR 2.78; 95\% CI 1.96, 3.96). Physician factors (age, gender, speciality) and patient factors (severity of depression, age, education, smoking, number of current physical conditions and functional syndromes) were associated with initial

FINDER was funded by Eli Lilly and Company Limited, Windlesham, UK and Boehringer Ingelheim GmbH, Ingelheim, Germany.

* Corresponding author. Tel.: +49 351458 2772; fax: +49 3514584324 .

E-mail addresses: michael.bauer@uniklinikum-dresden.de (M. Bauer), Brigitta.Monz@ing.boehringer-ingelheim.com (B.U. Monz), amontejo@usal.es (A.L. Montejo), quail_deborah@lilly.com (D. Quail),nicolas.dantchev@htd.ap-hop-paris.fr (N. Dantchev), koen.demyttenaere@med.kuleuven.be (K. Demyttenaere), garcia-cebriana@lilly.com (A. Garcia-Cebrian), luigi.grassi@unife.it (L. Grassi), d.perahia@lilly.com (D.G.S. Perahia), reed_catherine@lilly.com (C. Reed), a.tylee@iop.kcl.ac.uk (A. Tylee).

${ }^{1}$ Tel.: +49 6132779 3362; fax: +49 6132774233 .

${ }^{2}$ Tel.: +34 923126 596/97; fax: +34923265482.

${ }^{3}$ Tel.: +44 (0) 1276483293 ; fax: +44 (0) 1276484800 .

${ }^{4}$ Tel.: +33 (0) 1423484 35; fax: +33 (0) 142348433 .

5 Tel.: +32163 48705; fax: +3216348700.

6 Tel.: +44 (0) 1276483028 ; fax: +44 (0) 1276483192.

7 Tel.: +390532 236409 ; fax +390532 212240 .

${ }^{8}$ Tel.: +44 (0) 1276 483755/+44 (0)20 8746 8733; fax: +44 (0) 1276 483711/+44 (0)20 87468711 .

9 Tel.: +44 (0) 1276483243 ; fax: +44 (0) 1276483192 .

${ }^{10}$ Tel.: +44 (0) 207848 0150; fax: +44 (0) 2078480333 .
} 
antidepressant choice in some models. In conclusion, the prescribing of antidepressants varies by country, and the type of antidepressant chosen is influenced by physician- as well as patient-related factors.

(C) 2007 Elsevier Masson SAS. All rights reserved.

Keywords: Antidepressants; Depression; Europe; FINDER; Prescribing patterns

\section{Introduction}

Depression is a highly prevalent disorder in Europe and is often managed in primary care [24]. Antidepressant drugs are effective in the treatment of depression and are the most widely used form of treatment $[7,8]$. Over the past decade, there has been an increase in the number and types of antidepressants available. They have a wide range of mechanisms of action but are primarily targeted at modulating the function of the neurotransmitters serotonin and/or norepinephrine and/or dopamine.

For many years, tricyclic and tetracyclic antidepressants (TCAs) were the first-line treatment choice for depression in Europe, but recent studies indicate that selective serotonin reuptake inhibitors (SSRIs) are now the initial choice of antidepressant in many countries and are the most commonly prescribed group of antidepressant drugs [16,18,20,23,32]. However, surveys have shown that there are differences in the prescribing of antidepressants between European countries $[12,30]$.

Systematic reviews, meta-analyses and evidence-based treatment guidelines have found that different antidepressants have comparable efficacy in the majority of patients with depression seen in primary care or outpatient psychiatric settings $[6,7,17,19,33]$. However, for example, SSRIs are generally better tolerated than TCAs and are less likely to be discontinued due to side effects $[3,6,19,22]$. Early discontinuation of antidepressant therapy may increase the risk of relapse or recurrence of depression [10].

Numerous factors influence the choice of antidepressant drug prescribed by physicians, including physician and patient characteristics; e.g. physician speciality and country of practice, severity of depression, and previous depressive episodes $[28,35,38]$. Current practice guidelines recommend that physicians should choose an antidepressant drug based on past experience of treatment, side effects, patient preference and cost $[2,4,7,22]$. The presence of comorbid psychiatric or general physical conditions may also influence the choice [6].

The Factors Influencing Depression Endpoints Research (FINDER) study is a pan-European study designed to increase understanding of the factors that influence health-related quality of life (HRQoL) outcomes for patients with a depressive episode in routine primary and specialist care settings [15]. The study design and characteristics of the population at baseline are described in a companion paper. The objectives of the present analysis are to determine the current prescribing patterns of antidepressants in 12 European countries and to examine how physician and patient characteristics influence the selection of an initial antidepressant in the FINDER study population.

\section{Methods}

\subsection{Study design and subjects}

FINDER is a 6-month, observational, multicentre study conducted in 12 European countries: Austria, Belgium, France, Germany, Ireland, Italy, The Netherlands, Norway, Portugal, Sweden, Switzerland and the UK. The study design and methods have been reported in detail elsewhere [15]. Briefly, the participating investigators were primary care physicians (PCPs) or specialists (mostly psychiatrists). Eligible patients were enrolled consecutively within each participating centre from May 2004 to September 2005. The study population comprised adult patients (aged $\geq 18$ years) presenting within the normal course of care with a clinical diagnosis of depression and whose physician had already decided to commence antidepressant treatment for a first episode or a new recurrent episode of depression. The study was approved in all countries according to local requirements for ethics and/or regulatory approvals for observational studies, and all patients gave written informed consent.

Data were collected at baseline (the routine visit at which the patient agreed to enter the study) and at 3 and 6 months post-baseline during visits that were part of the routine clinical care of the patient. Only baseline data are presented in this report.

\subsection{Data collected}

The data recorded at baseline included patient socio-demographics, psychiatric history such as the number of previous episodes of depression and the occurrence of any specified psychiatric illnesses in the previous 24 months, the duration of the current depressive episode and the presence of comorbid chronic physical conditions and comorbid functional syndromes from a specific list.

Information on the use of antidepressants in the previous 24 months was collected as well as the type and dose of antidepressant(s) prescribed at the baseline visit. For the purpose of the current analyses, antidepressant medications were grouped as follows: SSRIs (citalopram, escitalopram, fluoxetine, fluvoxamine, paroxetine, sertraline); serotonin and norepinephrine reuptake inhibitors (SNRIs; duloxetine, milnacipran, venlafaxine); TCAs (amoxapine, amitriptyline, clomipramine, desipramine, dothiepin/dosulepin, doxepin, imipramine, lofepramine, maprotiline, mianserin, nortriptyline, opipramol, trimipramine); others (including herbal remedies [hypericum, St. John's wort], flupentixol, lithium, monoamine oxidase inhibitors [MAOIs; moclobemide, phenelzine, tranylcypromine], 
mirtazapine, reboxetine, trazodone, tryptophan, viloxazine); and combinations of antidepressants from more than one of the above groups.

The patient-rated Hospital Anxiety and Depression Scale (HADS) [36] was completed at baseline: this consists of seven items for depression (subscale HADS-D) and seven items for anxiety (subscale HADS-A). Patients also rated their overall health state on the day of assessment using the European Quality of Life-5 Dimensions (EQ-5D) visual analogue scale (VAS), which ranges from 0 (worst imaginable health state) to 100 (best imaginable health state) [9]. Overall pain severity was rated by patients using a VAS $(0-100 \mathrm{~mm})$, with patients scoring $\geq 30 \mathrm{~mm}$ considered to have moderate/severe pain.

\subsection{Statistical analysis}

Data describing the study population and prescribing pattern of antidepressants are presented as means, standard deviations (SD), frequencies or percentages, as appropriate.

To examine factors associated with the choice of the antidepressant prescribed at baseline, the following binary outcomes were modelled using generalised estimating equations (GEE): (1) patients prescribed SSRIs alone at baseline (yes vs. no); (2) patients prescribed SNRIs alone at baseline (yes vs. no); (3) patients prescribed more than one antidepressant at baseline vs. only one antidepressant; and (4) for Germany only, patients prescribed TCAs alone at baseline (yes vs. no). The first two outcomes were chosen based on the prescribing frequency of the groups (i.e. SSRIs and SNRIs were the most and second most prescribed AD groups in FINDER), the third outcome was chosen to investigate factors associated with the initiation of more than one antidepressant, and the last outcome was chosen because more than a quarter of FINDER patients in Germany were prescribed TCAs (see Fig. 1).

The GEE analysis method was chosen because it is expected that for each investigator, the choice of prescription for one patient is not likely to be independent of his choice for another of his patients, unlike in a conventional logistic regression analysis in which a crucial assumption is that all observations (patients) are independent. We expect the choice of drug group prescribed to be influenced by characteristics of both the investigator and the patient. In the GEE analysis, patients are "clustered" within investigator sites, which means that observations are independent between clusters (investigators) but correlated within clusters. An "exchangeable" correlation matrix was used, which assumes that the correlation between each pair of patients seen by an investigator is the same, regardless of the order in which they were seen. This seems a reasonable assumption because of the relatively short period of time during which an investigator would have been enrolling patients into the study.

Independent variables used in the initial model for the first three outcomes were as follows: (1) investigator-related variables: age, gender, location of practice, and speciality; (2) patient-related variables: age, gender, body mass index, education level, occupational status, smoking, number of dependants, marital status, number of previous episodes of depression, antidepressant use in the previous 24 months, previous anxiety and/ or panic disorder, total number of current physical conditions and functional syndromes, duration of current depressive episode, pain (VAS overall pain score $>30$ ), EQ-5D VAS, severity of depression (HADS-D) and severity of anxiety (HADS-A); and (3) country.

For analysis of TCAs alone at baseline, the country was omitted since only German patients/investigators were included in the model.

Models were built using stepwise methods to include only those independent variables that were statistically significantly associated $(p \leq 0.05)$ with the outcome variable. The effect of adding other variables that were of borderline significance was investigated in the models. To be eligible for inclusion in the models, physicians and patients must have a non-missing result for the outcome variable and all of the independent variables. Data were analysed using SAS version 8.2 and are presented as odds ratios (OR) and $95 \%$ confidence intervals (CIs) for each of the comparisons.

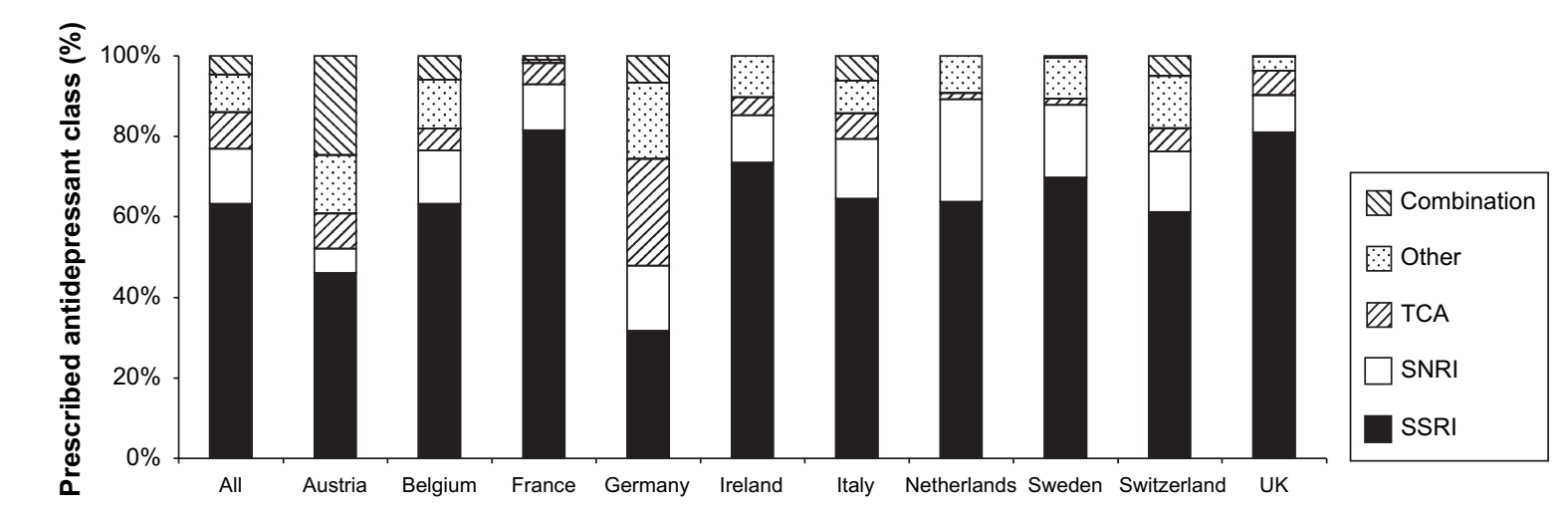

\begin{tabular}{|l|c|c|c|c|c|c|c|c|c|c|c|}
\hline $\mathrm{N}$ & 3468 & 163 & 239 & 606 & 649 & 68 & 513 & 196 & 199 & 139 & 608 \\
\hline $\begin{array}{l}\text { PCP/Specialist } \\
(\%)\end{array}$ & $48.3 / 51.7$ & $0 / 100$ & $54.5 / 45.5$ & $44.7 / 55.3$ & $38.5 / 61.5$ & $100 / 0$ & $0 / 100$ & $100 / 0$ & $36.1 / 63.9$ & $0 / 100$ & $98.3 / 1.7$ \\
\hline
\end{tabular}

Data for Norway and Portugal are not presented separately due to small sample size, but are included in the overall sample

Fig. 1. Prescribing of antidepressant group by country (for 10 of the 12 countries with more than 50 patients). 


\section{Results}

A total of 3515 patients were enrolled in the study and data from 3468 patients (98.7\%) were eligible for analysis. Forty seven patients were not eligible for analysis due to no prescription of antidepressants $(n=42)$ or missing age $(n=5)$. Most patients in the analysis sample were from Germany $(n=649)$, UK $(n=608)$, France $(n=606)$ and Italy $(n=513)$, with fewer than 50 patients each from Portugal $(n=48)$ and Norway $(n=40)$. Due to the small sample size, the results for patients in Portugal and Norway will not be presented individually or discussed further.

Across the 12 participating European countries, eligible patients were enrolled by a total of 437 investigators (211 PCPs [48.3\%] and 226 specialists [51.7\%]), although the type of investigator varied by country (Fig. 1). The majority of investigators $(62.7 \%)$ were in an urban practice setting. The mean age of the investigators was 50.1 years (SD 6.8) and $76.4 \%$ were male.

The baseline characteristics of the patients in the FINDER study have been reported elsewhere [15]. In short, HRQoL was largely impaired at enrolment when compared to population-based standards. The baseline values of all patient-related independent variables included in the current analyses, including scores for HRQoL and depression, are summarised in Table 1.

Table 1

Patient socio-demographics, psychiatric history and baseline findings in the FINDER study population $(n=3468)$

\begin{tabular}{lc}
\hline Variable & \\
\hline Socio-demographics & $46.8(14.7)$ \\
Age, years & 68.2 \\
Gender, \% female & $25.5(5.2)$ \\
BMI, kg/m & 52.3 \\
No or mandatory level of education, \% patients & 13.7 \\
Unemployed, \% patients & 50.1 \\
In paid work, \% patients & 32.3 \\
Smokers, \% patients & $1.1(1.3)$ \\
Number of dependants & 58.6 \\
Marital status, \% married/domestic partner & \\
Psychiatric history (in the last 24 months) & $1.8(1.4)$ \\
Number of previous episodes of depression ${ }^{\mathrm{a}}$ & 51.1 \\
Anxiety/panic disorder, \% patients & 38.2 \\
Antidepressant use, \% patients & \\
Medical history & 42.5 \\
Chronic physical condition present, \% patients & 39.9 \\
Current functional syndrome present, \% patients & 56.2 \\
Pain (moderate/severe), \% patients & \\
Baseline findings & $44.8(20.4)$ \\
EQ-5D VAS score (range 0-100) & $12.3(4.5)$ \\
HADS-D score (range 0-21) & $13.0(4.0)$ \\
HADS-A score (range 0-21) & $13.6(16.5)$ \\
Duration of current depressive episode, weeks & \\
\hline
\end{tabular}

Data are presented as mean (SD) unless indicated otherwise.

For abbreviations see text.

${ }^{\text {a }}$ For only those patients with $\geq 1$ previous depressive episode in the last 24 months.

\subsection{Prescribing patterns of antidepressants}

Fig. 1 shows that SSRIs were the most commonly prescribed antidepressant at baseline (63.3\% of all patients) followed by SNRIs (13.6\% of all patients). There was considerable variation between countries in the prescribing of different groups of antidepressants: the percentage of patients prescribed SSRIs ranged from $31.7 \%$ (Germany) to $81.5 \%$ (France), and that of SNRIs ranged from 6.1\% (Austria) to $25.5 \%$ (The Netherlands). TCAs were prescribed for $26.5 \%$ patients in Germany, but across the other countries were prescribed for between only $1.5 \%$ patients (Sweden and The Netherlands) and $8.6 \%$ patients (Austria). Combinations of more than one antidepressant were prescribed most frequently in Austria (24.5\% patients) and not at all in Ireland or The Netherlands.

The mean and median prescribed doses of the most frequently recorded antidepressants are summarised by physician speciality in Table 2. Of note, the mean doses of amitriptyline $(55.6 \mathrm{mg} /$ day $)$ and doxepin $(47.8 \mathrm{mg} /$ day) were below the currently recommended starting dose $(75 \mathrm{mg} / \mathrm{day})$ for these TCAs. Primary care physicians prescribed lower mean doses than specialists for amitriptyline, sertraline and venlafaxine, but higher mean doses for duloxetine and trazodone.

\subsection{Factors associated with initial antidepressant choice}

\subsubsection{Patients prescribed SSRIs alone}

The variables significantly associated with being prescribed SSRIs alone at baseline are summarised in Table 3. The factor with the strongest association was whether or not the patient had had any previous antidepressant use in the 24 months before the study; those who had previously taken an antidepressant were 0.64 times less likely to be prescribed a SSRI than those who had not. Older investigators, older patients and smokers were associated with a decreased likelihood of a SSRI being prescribed, whereas patients with further education were more likely to receive a SSRI.

\subsubsection{Patients prescribed SNRIs alone}

Two variables were significantly associated with a SNRI being prescribed at baseline ( $n=3431)$ : (1) female physicians were more likely to prescribe a SNRI than male physicians (OR 1.77; 95\% CI 1.27, 2.48), and (2) patients who had previous antidepressant use were more likely to receive a SNRI than those who had not used an antidepressant in the previous 24 months (OR 1.49; 95\% CI 1.18, 1.88). Additionally, some of the country comparisons to the UK were statistically significant, meaning that in those countries SNRI prescribing was more likely than in the UK as reference country (The Netherlands OR 3.64, 95\% CI 1.92, 6.89; Germany OR 1.76, 95\% CI 1.04, 2.98; Italy OR 1.82, 95\% CI 1.03, 3.23).

\subsubsection{Patients prescribed more than one antidepressant $v s$. a single antidepressant}

In two countries (Ireland and The Netherlands), none of the patients were prescribed more than one antidepressant. Since 
Table 2

Doses of most frequently prescribed antidepressants by speciality at enrolment

\begin{tabular}{|c|c|c|c|c|c|c|}
\hline & \multicolumn{2}{|c|}{ All $(n=3468)$} & \multicolumn{2}{|c|}{ Primary care physicians $(n=1818)$} & \multicolumn{2}{|c|}{ Specialists $(n=1650)$} \\
\hline & $\begin{array}{l}\text { Number of } \\
\text { patients }\end{array}$ & $\begin{array}{l}\text { Mean }(\mathrm{SD}) / \text { median } \\
\text { dose }(\mathrm{mg})\end{array}$ & $\begin{array}{l}\text { Number of } \\
\text { patients }\end{array}$ & $\begin{array}{l}\text { Mean }(\mathrm{SD}) / \text { median } \\
\text { dose }(\mathrm{mg})\end{array}$ & $\begin{array}{l}\text { Number of } \\
\text { patients }\end{array}$ & $\begin{array}{l}\text { Mean }(\mathrm{SD}) / \text { median } \\
\text { dose }(\mathrm{mg})\end{array}$ \\
\hline Amitriptyline & 113 & $55.6(39.2) / 50.0$ & 54 & $49.1(38.5) / 43.8$ & 59 & $61.5(39.1) / 50.0$ \\
\hline Citalopram & 521 & $20.0(7.9) / 20.0$ & 274 & $19.2(6.3) / 20.0$ & 247 & $21.0(9.2) / 20.0$ \\
\hline Doxepin & 70 & $47.8(33.6) / 50.0$ & 51 & $47.1(36.7) / 25.0$ & 19 & $49.7(23.9) / 50.0$ \\
\hline Duloxetine & 103 & $49.5(16.6) / 60.0$ & 38 & $56.8(11.6) / 60.0$ & 65 & $45.2(17.7) / 30.0$ \\
\hline Escitalopram & 426 & $11.2(4.5) / 10.0$ & 168 & $10.7(3.5) / 10.0$ & 258 & $11.5(5.0) / 10.0$ \\
\hline Fluoxetine & 686 & $20.7(7.5) / 20.0$ & 428 & $20.5(3.7) / 20.0$ & 258 & $21.0(11.3) / 20.0$ \\
\hline Mirtazapine & 253 & $26.5(9.1) / 30.0$ & 76 & $25.0(8.1) / 30.0$ & 177 & $27.2(9.4) / 30.0$ \\
\hline Paroxetine & 337 & $21.5(7.1) / 20.0$ & 162 & $21.5(6.9) / 20.0$ & 175 & $21.5(7.4) / 20.0$ \\
\hline Sertraline & 323 & $58.1(25.5) / 50.0$ & 100 & $51.5(16.1) / 50.0$ & 223 & $61.1(28.3) / 50.0$ \\
\hline Trazodone & 78 & $88.6(43.2) / 100.0$ & 10 & $117.5(29.0) / 100.0$ & 68 & $84.3(43.4) / 75.0$ \\
\hline Venlafaxine & 391 & $95.6(44.3) / 75.0$ & 180 & 80.7 (30.6)/75.0 & 211 & $108.2(49.9) / 75.0$ \\
\hline
\end{tabular}

Includes all antidepressants prescribed to at least 50 patients.

this would cause problems of non-convergence of the models, two analyses are presented, one excluding these two countries and the other pooling Ireland with the UK and The Netherlands with Belgium. In the second analysis, the reference country was UK/Ireland.

Table 4 lists the variables significantly associated with being prescribed more than one antidepressant at baseline in both analyses. Previous treatment with an antidepressant was the covariate most strongly associated with receiving more than one antidepressant at baseline. A one-point increase in the HADS-D score was associated with an increased likelihood of being prescribed a combination of antidepressants by a factor of 1.07. Physician age was also associated with an increased likelihood of being prescribed a combination of antidepressants by a factor of 1.22 for every additional 5 years of age (model 2).

\subsubsection{Patients prescribed TCAs alone (in Germany)}

Table 5 summarises the variables significantly associated with being prescribed TCAs alone in Germany. The most influential factor was physician gender, with female physicians 0.20 times less likely to prescribe TCAs than male physicians. Also significant were the total number of current physical conditions and functional syndromes, with the odds of being prescribed TCAs increased by a factor of 1.13 for each additional

Table 3

Variables significantly associated with being prescribed SSRIs at enrolment (GEE analysis), $n=3357$

\begin{tabular}{|c|c|c|c|c|}
\hline & $\begin{array}{l}\text { Chi- } \\
\text { square }\end{array}$ & $p$-value & $\begin{array}{l}\text { Odds } \\
\text { ratio }(\mathrm{OR})\end{array}$ & $95 \% \mathrm{CI}$ \\
\hline $\begin{array}{l}\text { Any previous } \\
\text { antidepressant (yes vs. no) }\end{array}$ & 25.4 & $<0.0001$ & 0.64 & $0.54,0.76$ \\
\hline Physician age per 5 years & 7.6 & 0.006 & 0.88 & $0.80,0.96$ \\
\hline Patient age per 5 years & 10.4 & 0.001 & 0.95 & $0.93,0.98$ \\
\hline Smoking (yes vs. no) & 5.6 & 0.018 & 0.82 & $0.69,0.97$ \\
\hline $\begin{array}{l}\text { Education (further vs. } \\
\text { no/mandatory) }\end{array}$ & 5.7 & 0.017 & 1.22 & $1.04,1.44$ \\
\hline
\end{tabular}

Country was also statistically significant in the model with significant differences from the UK observed for all countries apart from France and Ireland. condition. Finally, German PCPs were 2.30 times more likely to prescribe TCAs than specialists.

\section{Discussion}

\subsection{Differences among countries}

In each of the 12 countries taking part in the FINDER study, SSRIs were the most common group of antidepressant prescribed for patients with a first episode of depression or a new episode of recurrent depression. TCAs were used in just over one-quarter of the patients in Germany and combinations of antidepressants were prescribed for approximately one-quarter of the patients in Austria. In the other countries examined individually, SNRIs were the second most common group of antidepressants prescribed. Several physician and patient characteristics influenced the choice of antidepressant prescribed, but the factor most consistently and strongly associated with antidepressant selection was previous antidepressant use in the 24 months before the study.

Since SSRIs tend to be the first choice antidepressant, those patients who have taken an antidepressant previously and are entering the FINDER study with a recurrent episode of depression are more likely to be prescribed a SNRI $(\mathrm{OR}>1)$ than patients who had not used antidepressants in the previous 24 months.

The finding of SSRIs being the predominant antidepressant group prescribed is consistent with previous reports in European and other countries [16,18,21,23,29,32]. Although SSRIs are considered no more effective than other classes of antidepressants, they are recommended because they can be administered once daily, require less dose-titration than TCAs, and are associated with fewer side effects and lower cardiovascular toxicity in overdose than TCAs [7,25].

There was considerable variation in the types of antidepressant prescribed across the different countries taking part in the study. This may be due in part to the differing availability and prices of antidepressants as well as recommendations in national guidelines, reimbursement status and promotional activities in 
Table 4

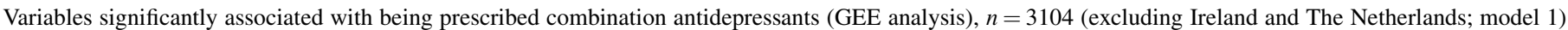
and $n=3360$ (including all countries; model 2)

\begin{tabular}{|c|c|c|c|c|c|c|c|c|}
\hline & \multicolumn{4}{|l|}{ Model 1} & \multicolumn{4}{|l|}{ Model 2} \\
\hline & Chi-square & $p$-value & $\begin{array}{l}\text { Odds } \\
\text { ratio }(\mathrm{OR})\end{array}$ & $95 \% \mathrm{CI}$ & Chi-square & $p$-value & $\begin{array}{l}\text { Odds } \\
\text { ratio }(\mathrm{OR})\end{array}$ & $95 \% \mathrm{CI}$ \\
\hline Any previous antidepressant (yes vs. no) & 31.0 & $<0.0001$ & 2.71 & $1.91,3.84$ & 32.7 & $<0.0001$ & 2.78 & $1.96,3.96$ \\
\hline HADS-D & 7.4 & 0.006 & 1.07 & $1.02,1.13$ & 7.5 & 0.006 & 1.07 & $1.02,1.13$ \\
\hline Physician age per 5 years & 5.1 & 0.024 & 1.23 & $1.03,1.48$ & 4.3 & 0.038 & 1.22 & $1.01,1.48$ \\
\hline
\end{tabular}

All of the country comparisons to the UK (model 1) or UK/Ireland (model 2) are statistically significant apart from Sweden.

each country. Country was included into the regression models to account for these known variations, and thus all findings related to the physician and/or patient characteristics were adjusted for those unmeasured country-specific factors. Differences in the types of antidepressant prescribed will also be influenced by the availability and use of other forms of treatment in these countries, such as psychological therapy, as well as the relative proportions of PCPs and specialists taking part in the FINDER study.

Our findings of a high use of TCAs in Germany are supported by prescribing patterns of antidepressants in two recent studies, one of children and adolescents in Germany [13] and one of outpatients within a German state based on claims data [31]. SNRIs are available in all the countries taking part in FINDER, but the relatively low use of SNRIs in the UK (9.2\%) may reflect the high proportion of PCPs in the study and UK guideline recommendations that venlafaxine should only be initiated and managed by specialists [22].

Antidepressant combinations are frequently used in clinical practice [11]. Interestingly, in the FINDER study, the use of combinations of antidepressants was much more common in Austria $(24.5 \%)$ than in any of the other countries examined individually (each less than 7\%). This may be due to the characteristics of the patient population in these countries. On the other hand, all investigators in Austria were specialists and may treat depression more aggressively than PCPs to achieve full remission [1]. Moreover, it has been recommended in the UK, for example, that antidepressant combinations should only be initiated under specialist supervision [22].

Most antidepressants were used at their recommended doses. Notable exceptions were amitriptyline and doxepin (both TCAs), which were both initiated at mean daily doses below the recommended dose, although the evidence base

Table 5

Variables significantly associated with being prescribed TCA(s) in Germany (GEE analysis), $n=641$

\begin{tabular}{lllll}
\hline & $\begin{array}{l}\text { Chi- } \\
\text { square }\end{array}$ & $p$-value & $\begin{array}{l}\text { Odds } \\
\text { ratio (OR) }\end{array}$ & $95 \%$ CI \\
\hline $\begin{array}{l}\text { Physician gender } \\
\quad \text { female vs. male) }\end{array}$ & 11.4 & 0.001 & 0.20 & $0.08,0.51$ \\
$\begin{array}{l}\text { Physician speciality } \\
\quad \text { PCP vs. specialist) }\end{array}$ & 4.8 & 0.028 & 2.30 & $1.09,4.84$ \\
$\begin{array}{l}\text { Total number of current physical } \\
\text { conditions and functional } \\
\text { syndromes }\end{array}$ & 9.3 & 0.002 & 1.13 & $1.04,1.22$ \\
\hline
\end{tabular}

PCP, primary care physician. for the currently recommended doses is not well established [14]. Although recent meta-analyses have shown that lowdose TCAs $(\leq 100 \mathrm{mg} /$ day $)$ are effective for the treatment of depression [5,14], there remain concerns that TCAs are often prescribed at less than adequate doses. Prescription of TCAs at low doses, especially by PCPs, may be related to concerns about the side effects associated with TCAs. In addition, the mean dose of duloxetine prescribed by specialists was below the recommended daily dose of $60 \mathrm{mg}$, which may indicate their preference for up-titration of patients to the recommended dose [34].

\subsection{Factors influencing prescribing patterns}

Practice guidelines recommend that physicians should choose an antidepressant drug based on the past experience of treatment, side effects, patient preference and cost $[2,7,22]$. We found that previous antidepressant use was consistently and most strongly associated with the selection of the antidepressant. This suggests that past experience and outcomes of previous treatments do indeed influence the choice of antidepressant drug. Our findings are consistent with those of the survey by Zimmerman et al. [38], where prior treatment history was an important factor influencing antidepressant medication choice by psychiatrists. Rush et al. [26] investigated switching antidepressants due to intolerability or not achieving remission with initial treatment with citalopram. In this particular context, remission rates were not dependent on the class of the new antidepressant prescribed. We will be investigating switching patterns and the associated outcomes during the FINDER 6-month study period in further analyses of the longitudinal data.

Physician age and gender were important factors influencing antidepressant selection in some models. In particular, physician age was significant for SSRIs but not SNRIs. Thus, this does not support the hypothesis that older physicians tend to prescribe drugs that have been available for longer periods of time. Female physicians were more likely than male physicians to prescribe SNRIs, and in Germany, were much less likely to prescribe TCAs. It is unclear why male and female physicians differ in their prescribing decision making. Perhaps surprisingly, physician type was not significantly associated with antidepressant selection except in Germany, where PCPs were much more likely to prescribe TCAs than specialists. Previous studies have not compared factors 
influencing antidepressant prescription in the primary care and specialist settings.

Severity of depression was only associated with the prescription of combinations of antidepressants; patients with more severe depression (higher HADS-D score) had a greater likelihood of receiving a combination of antidepressants than patients with less severe depression. This is in line with guideline recommendations that combinations of antidepressant medications can be used for patients with severe depression or treatment-resistant depression [2,22], although there is little controlled data to support the utility and efficacy of this strategy [7].

Certain patient socio-demographic characteristics were associated with the group of antidepressant prescribed at the baseline visit. Younger patients, non-smokers and those with further education were more likely to be prescribed SSRIs vs. other antidepressants. Further research is needed to investigate why these patient characteristics influence antidepressant prescribing. However, a previous study in the United States found that younger patients with depression (aged less than 50 years) were more likely to receive a SSRI or SNRI than older patients [27].

Antidepressant selection was not influenced by factors such as current patient functioning (EQ-5D VAS), severity of anxiety (HADS-A score) or comorbidity, except in Germany, where TCAs were more likely to be prescribed for patients with more concurrent physical conditions and functional syndromes. In contrast, Zimmerman et al. [38] found that the presence of comorbid conditions and high levels of anxiety symptoms influenced antidepressant selection by psychiatrists. However, the data were collected from only 10 psychiatrists compared with 437 investigators (211 PCPs and 226 specialists) in the present study.

\subsection{Study strengths and limitations}

The strengths of the FINDER study are that it is a large study in many European countries and includes samples of PCPs and specialists who care for patients with depression. In addition, many patients taking part in the study had comorbidities that would have excluded them from randomised controlled trials, but who represent the "real-world" population of patients with depression [37]. Furthermore, as the treatment approaches were not dictated by the study protocol, they reflect the usual care of depression in routine clinical practice. Since some investigator characteristics were collected as well, we included them in our analyses and, by adjusting for patient characteristics, were able to investigate these prescriber characteristics separately.

This study has several limitations. Firstly, we did not collect any information on patient preferences, an important factor to consider when prescribing antidepressants [22], and how this may or may not have influenced the prescribing behaviour of investigators. Secondly, the patient sample overall and within each country may not be representative of the patients treated in an outpatient setting for depression in the respective country. Moreover, it is likely that investigators participating in FINDER, especially PCPs, had an interest in depression as a research area and may, therefore, be better informed about depression than other investigators who declined to participate in the study. This may indicate that we have underestimated the importance of the physician-related associated factors.

\section{Conclusions}

The prescribing of antidepressants for patients with a clinical diagnosis of depression differs by country and is influenced by both physician and patient characteristics. Our analysis indicates that the recommendation for previous antidepressant experience to be taken into account is being largely followed in routine clinical practice.

\section{Acknowledgements}

The authors acknowledge the help of Deirdre Elmhirst, $\mathrm{PhD}$, in preparing the manuscript.

\section{References}

[1] Agüera LF, Rojo JE, Ros S, de la Gándara J, de Pedro JM. Antidepressant combinations: epidemiological considerations. Acta Psychiatr Scand 2005;112(Suppl. 428):7-10.

[2] American Psychiatric Association. Practice guideline for the treatment of patients with major depressive disorder (revision). Am J Psychiatry 2000;157(Suppl. 4):1-45.

[3] Anderson IM. Selective serotonin reuptake inhibitors versus tricyclic antidepressants: a meta-analysis of efficacy and tolerability. J Affect Disord 2000;58:19-36.

[4] Anderson IM, Nutt DJ, Deakin JFW. Evidence-based guidelines for treating depressive disorders with antidepressants: a revision of the 1993 British Association for Psychopharmacology guidelines. J Psychopharmacol 2000;14:3-20.

[5] Arroll B, Macgillivray S, Ogston S, Reid I, Sullivan F, Williams B, et al. Efficacy and tolerability of tricyclic antidepressants and SSRIs compared with placebo for treatment of depression in primary care: a meta-analysis. Ann Fam Med 2005;3:449-56.

[6] Bauer M, Bschor T, Pfennig A, Whybrow PC, Angst J, Versiani M, et al. World Federation of Societies of Biological Psychiatry (WFSBP) guidelines for biological treatment of unipolar depressive disorders in primary care. World J Biol Psychiatry 2007;8:67-104.

[7] Bauer M, Whybrow PC, Angst J, Versiani M, Möller HJ. World Federation of Societies of Biological Psychiatry (WFSBP) guidelines for biological treatment of unipolar depressive disorders, part 1: acute and continuation treatment of major depressive disorder. World J Biol Psychiatry 2002;3:5-43.

[8] Bauer M, Whybrow PC, Angst J, Versiani M, Möller HJ. World Federation of Societies of Biological Psychiatry (WFSBP) guidelines for biological treatment of unipolar depressive disorders, part 2: maintenance treatment of major depressive disorder and treatment of chronic depressive disorders and subthreshold depressions. World J Biol Psychiatry 2002;3:69-86.

[9] Brooks R, with the EuroQoL Group. EuroQol: the current state of play. Health Policy 1996;37:53-72.

[10] Claxton AJ, Li Z, McKendrick J. Selective serotonin reuptake inhibitor treatment in the UK: risk of relapse or recurrence of depression. $\mathrm{Br}$ J Psychiatry 2000;177:163-8.

[11] De la Gandara J, Aguera L, Rojo JE, Ros S, de Pedro JM. Use of antidepressant combinations: which, when and why? Results of a Spanish survey. Acta Psychiatr Scand 2005;112(Suppl. 428):32-6.

[12] ESEMeD/MHEDEA 2000 Investigators. Psychotropic drug utilization in Europe: results from the European Study of the Epidemiology of Mental Disorders (ESEMeD) project. Acta Psychiatr Scand 2004;109(Suppl. 420):55-64. 
[13] Fegert JM, Kolch M, Zito JM, Glaeska G, Jahnsen K. Antidepressant use in children and adolescents in Germany. J Child Adolesc Psychopharmacol 2006;16:197-206.

[14] Furukawa TA, McGuire H, Barbui C. Meta-analysis of effects and side effects of low dosage tricyclic antidepressants in depression: systematic review. BMJ 2002;325:991-1000.

[15] Garcia-Cebrian A, Bauer M, Montejo AL, Dantchev N, Demyttenaere K, Gandhi P, et al. Characteristics of depressed outpatients entering the Factors Influencing Depression Endpoints Research (FINDER) study. Eur Psychiatry 2008;23:57-65.

[16] Guaiana G, Andretta M, Corbari L, Mirandola M, Sorio A, D’Avanzo B, et al. Antidepressant drug consumption and public health indicators in Italy, 1955 to 2000. J Clin Psychiatry 2005;66:750-5.

[17] Hansen RA, Gartlehner G, Lohr KN, Gaynes BN, Carey TS. Efficacy and safety of second-generation antidepressants in the treatment of major depressive disorder. Ann Intern Med 2005;143:415-26.

[18] Lawrenson RA, Tyrer F, Newson RB, Farmer RD. The treatment of depression in UK general practice: selective serotonin reuptake inhibitors and tricyclic antidepressants compared. J Affect Disord 2000;59:149-57.

[19] MacGillivray S, Arroll B, Hatcher S, Ogston S, Reid I, Sullivan F, et al. Efficacy and tolerability of selective serotonin reuptake inhibitors compared with tricyclic antidepressants in depression treated in primary care: systematic review and meta-analysis. BMJ 2003;326:1014-9.

[20] Martin-Agueda B, Lopez-Munoz F, Rubio G, Guerra JA, Silva A, Alamo C. Management of depression in primary care: a survey of general practitioners in Spain. Gen Hosp Psychiatry 2005;27:305-12.

[21] Montejo AL, Gilaberte I, Fombellida C, Hylan TR, Sacristan JA. Pattern of usage of new antidepressants in clinical practice. Actas Luso Esp Neurol Psiquiatr 1998;26:75-81 [in Spanish].

[22] National Institute for Clinical Excellence. Depression: management of depression in primary and secondary care. Clinical Guideline No. 23, ; December 2004. Available from www.nice.org.uk [accessed 4.12.2007].

[23] Olie JP, Elomari F, Spadone C, Lepine JP. Antidepressant consumption in the global population in France. Encephale 2002;28:411-7 [in French].

[24] Paykel ES, Brugha T, Fryers T. Size and burden of depressive disorders in Europe. Eur Neuropsychopharmacol 2005;15:411-23.

[25] Peretti S, Judge R, Hindmarch I. Safety and tolerability considerations: tricyclic antidepressants vs. selective serotonin reuptake inhibitors. Acta Psychiatr Scand 2000;102(Suppl. 403):17-25.
[26] Rush AJ, Trivedi MH, Wisniewski SR, Stewart JW, Nierenberg AA, Thase ME, et al. Bupropion-SR, sertraline, or venlafaxine-XR after failure of SSRIs for depression. N Engl J Med 2006;354:1231-42.

[27] Sclar DA, Robison LM, Skaer TL, Galin RS. What factors influence the prescribing of antidepressant pharmacotherapy? An assessment of national office-based encounters. Int J Psychiatry Med 1998;28:407-19.

[28] Sleath B, Shih YC. Sociological influences on antidepressant prescribing. Soc Sci Med 2003;56:1335-44.

[29] Stafford RS, MacDonald EA, Finkelstein SN. National patterns of medication treatment for depression, 1987 to 2001. Primary Care Companion J Clin Psychiatry 2001;3:232-5.

[30] Tylee A, Gastpar M, Lepine JP, Mendlewicz J. DEPRES II (Depression Research in European Society II): a patient survey of the symptoms, disability and current management of depression in the community. Int Clin Psychopharmacol 1999;14:139-51.

[31] Ufer M, Meyer SA, Junge O, Selke G, Volz HP, Hedderich J, et al. Patterns and prevalence of antidepressant drug use in the German state of Baden-Wuerttemberg: a prescription based analysis. Pharmacoepidemiol Drug Saf 2007;16:1153-60.

[32] Van Marwijk HW, Bijl D, Ader HJ, de Haan M. Antidepressant prescription for depression in general practice in The Netherlands. Pharm World Sci 2001;23:46-9.

[33] Williams JW, Mulrow CD, Chiquette E, Hitchcock P, Aguilar C, Cornell J. A systematic review of newer pharmacotherapies for depression in adults: evidence report summary. Ann Intern Med 2000;132:743-56.

[34] Wohlreich MM, Martinez JM, Mallinckrodt CH, Prakash A, Watkin JG, Fava M. An open-label study of duloxetine for the treatment of major depressive disorder: comparison of switching versus initiating treatment approaches. J Clin Psychopharmacol 2005;25:552-60.

[35] Zetin M, Hoepner CT, Bjornson L. Rational antidepressant selection: applying evidence-based medicine to complex real-world patients. Psychopharmacol Bull 2006;39:38-104.

[36] Zigmond AS, Snaith RP. The hospital anxiety and depression scale. Acta Psychiatr Scand 1983;67:361-70.

[37] Zimmerman M, Mattia JI, Posternak MA. Are subjects in pharmacological treatment trials for depression representative of patients in routine clinical practice? Am J Psychiatry 2002;159:469-73.

[38] Zimmerman M, Posternak M, Friedman M, Attiullah N, Baymiller S, Boland R, et al. Which factors influence psychiatrists' selection of antidepressants? Am J Psychiatry 2004;161:1285-9. 